\title{
Decrease of cholesterol content in milk by sorption onto $\beta$-cyclodextrin crosslinked with tartaric acid; considerations and implications
}

\author{
Martin Kukula, Lukáš Kolarič, Peter Šimko \\ Slovak University of Technology in Bratislava, \\ Faculty of Chemical and Food Technology, Institute of Food Science and Nutrition, \\ Radlinského 9, 81237 Bratislava, Slovak Republic \\ qsimko@stuba.sk
}

\begin{abstract}
Elevated cholesterol intake can induce the development of cardiovascular diseases in man, especially with long term animal origin foods consumption. Therefore, this work deals with the possibility of cholesterol content decrease in milk applying $\beta$-cyclodextrin crosslinked with tartaric acid (BCDcTA) as a removal agent. Evaluation of statistic data on food consumption in the Slovak Republic in 2018 aimed at total cholesterol daily intake and effects of "milky" cholesterol content decrease on total cholesterol balance. During the experiments, various amounts of $\beta$ CDcTA addition to milk were studied resulting in optimal $5 \%$ addition resulting in the cholesterol content decrease by $85.4 \%$ in comparison to original cholesterol content. For monitoring purposes, an HPLC method analysing cholesterol content in saponified milk was employed. The food consumption data analysis showed that total per capita daily cholesterol intake was $369.8 \mathrm{mg}$, from which $86 \mathrm{mg}$ was assigned to the cholesterol contained in milk and dairy products while the application of cholesterol removal procedure could decrease the total per capita daily cholesterol intake to $296.3 \mathrm{mg}$ ("milky" cholesterol amount equal to $12.6 \mathrm{mg}$ ), which in below the recommended value of $300 \mathrm{mg}$ daily intake still valid in the Slovak Republic. This approach might prove as a meaningful step to weaken health problems associated with high long term intake of cholesterol contained in foods of animal origin.
\end{abstract}

Keywords: cholesterol intake, milk, HPLC, health, crosslinked $\beta$-cyclodextrin, cholesterol-free foods, annual consumption

\section{Introduction}

Cholesterol is a soft, waxy compound found among the lipids or fats in the bloodstream and in all cell membranes. It is a non-saponifiable lipid, essential in maintaining vital functions of organisms, as it participates in the formation of cell membranes, several hormones, vitamin $\mathrm{D}$, and bile acids needed for food fat digestion (Parish et al., 2002). On the other hand, elevated intake of cholesterol contained in foods of animal origin could result in serious cardiovascular diseases (CVD) such as arteriosclerosis and stroke. Larsson et al. (2012) analysed data such as education, weight, height, cigarette smoking, physical activity, family history of myocardial infarction, aspirin use, alcohol consumption, and diet of 34,670 women and stated that dietary cholesterol can be positively associated with the risk of total stroke and cerebral infarction. On the base of such information and real CVD situation in Slovak population, cholesterol daily intake recommended value has been set to $300 \mathrm{mg}$ /adult person in the Slovak Republic by health authorities (Official Report of the Ministry of Health of the Slovak Republic, 2015). To the contrary, contemporary guidelines for CVD risk reduction from the American Heart Association and American College of
Cardiology as well as "2015-2020 Dietary Guidelines for Americans" have already not issued explicit guidance for dietary cholesterol intake due to inconsistencies in the evidence base and the inherent difficulty in conducting and interpreting studies to isolate the independent effect of dietary cholesterol on GVD (Carson et al., 2020). Similarly, according to the recent European Society of Cardiology and European Atherosclerosis Society guidelines for the management of dyslipidaemias, the key initiating event in the atherogenesis is the retention of low-density lipoprotein cholesterol (LDL-C) and other cholesterol-rich apolipoprotein containing lipoproteins within the arterial wall (Mach et al., 2020). Indeed, evidence has confirmed that retention of LDL-C and other cholesterol-rich apolipoprotein containing lipoproteins within the arterial wall is the key initiating event in atherogenesis (Ference e al., 2017). One way or another, limitation of cholesterol content in foods could be one of the key issues targeting health problems associated with elevated blood cholesterol content. One of effective procedures limiting the blood cholesterol content is focusing on health dietary patterns such as the Mediterranean-style diet (Fung et al., 2005), or Dietary Approaches to Stop Hypertension (DASH) (Appel et al., 1997) which are inherently associated 
with lowered blood cholesterol content due to daily intake of $<300 \mathrm{mg}$ of cholesterol (Carson et al., 2020). Another approach to lowering cholesterol content in diet can be based on technological processes during raw materials treatments resulting in minimised cholesterol content in comparison with the original matrix. Alonso et al. (2009) demonstrated that beta cyclodextrin $(\beta-\mathrm{CD})$ addition of $0.4 \%, 0.6 \%, 0.8 \%$ or $1.0 \%$ removes cholesterol from milk in the range between $65.4 \%$ and $95.3 \%$, when maximum cholesterol removal was seen within $6 \mathrm{~h}$ of treatment with $\beta$-CD-cholesterol complex removal by centrifugation. Han et al. (2005) removed cholesterol in homogenised milk with $\beta$-cyclodextrin crosslinked with adipic acid and in this case, cholesterol removal of above $90 \%$ was observed. Also, Lee et al. (2012) studied the use of crosslinking $\beta$-CD for cholesterol removal in milk and cream and concluded that cross-linked $\beta$-CD with $15 \%$ adipic acid showed better $\beta$-CD recovery and reuse, and higher cholesterol removal rate at repeated recycle than cross-linked $\beta$-CD with $2 \%$ adipic acid. Methods for cholesterol content determination in food can be divided into three major categories: classical chemical methods based on the Abell-Kendall protocol, fluorometric and colorimetric enzymatic assays, and analytical instrumental approaches such as gas and liquid chromatography (Li et al., 2019). The most appropriate and frequently applied sample treatment before HPLC include direct saponification followed by the extraction of unsaponifiable residue into a non-polar solvent. Direct saponification is preferred due to simple conversion of non-polar fatty acid esters to polar products with the following effective removal by multiple extraction with n-hexane (Bauer et al., 2014; Albuquerque et al., 2016; Kolarič and Šimko, 2020a). Alternatively, a mixture of polar and nonpolar solvents has been proposed to provide more efficient cholesterol extraction from various food matrix where cholesterol is usually bound by many other biological compounds such as lipoproteins, proteins, and phospholipids (Dinh et al., 2011). The first aim of this work was thus to study conditions of cholesterol removal from milk by application of $\beta$-CD crosslinked with tartaric acid ( $\beta$ CDcTA) while the second aim was to consider total cholesterol daily intake per capita, its removal from milk and dairy products and effect of the removal on total cholesterol balance in Slovak population.

\section{Materials and methods}

\section{Sample}

Cow milk (3.5 \% fat, Rajo a.s., Bratislava, Slovakia) was bought in a local market.

\section{Chemicals}

All solvents and chemicals were of analytical grade. Cholesterol standard was from Sigma-Aldrich with the purity of $\geq 99 \%$. Chloroform, n-hexane, ethanol, and sodium sulphate anhydrous were purchased from Centralchem s.r.o. (Bratislava, Slovakia). Methanol and acetonitrile (HPLC grade) were purchased from Fisher Chemical (Loughborough, UK). Tartaric acid was provided by Lachema Brno (Czech Republic).

\section{Sample preparation}

The amount of $0.5 \mathrm{~g}$ of milk was refluxed with $15 \mathrm{~mL}$ of $1 \mathrm{~mol} / \mathrm{L}$ methanolic solution of $\mathrm{KOH}$ for $15 \mathrm{~min}$. Then, cooled matter was extracted twice with a mixture of $n$-hexane and chloroform (1:1, $\mathrm{v} / \mathrm{v}$ ) to obtain $15 \mathrm{~mL}$ of total extract. To increase the polarity of saponifiable residue, $10 \mathrm{~mL}$ of deionised water was added. To avoid the formation of emulsion during the extraction, $1 \mathrm{~mL}$ of ethanol (96\%) was added to the saponified matter. Then, the extract was filtrated through anhydrous $\mathrm{Na}_{2} \mathrm{SO}_{4}$, and evaporated using a rotary vacuum evaporator (Heidolph, Germany) until dryness; the residue was dissolved in $5 \mathrm{~mL}$ of methanol, filtered using a syringe PTFE filter with a $0.2 \mu \mathrm{m}$ membrane (Agilent Technologies, Santa Clara, CA, USA), and analysed by HPLC.

\section{HPLC conditions}

HPLC was performed using an Agilent Technologies 1260 infinity system (Agilent, Santa Clara, CA, USA) equipped with a vacuum degasser, quarterly pump, autosampler, and a UV-DAD detector operating at $205 \mathrm{~nm}$. Isocratic elution was performed at the flow rate of $0.5 \mathrm{~mL} / \mathrm{min}$ mobile phase composed of acetonitrile/methanol 60:40 (v/v). The injection volume was $10 \mu \mathrm{L}$ and the temperature was set at $30{ }^{\circ} \mathrm{C}$. Zorbax Eclipse Plus C18 column $(2.1 \times 50 \mathrm{~mm}, 3.5 \mu \mathrm{m}$ particle size, Agilent, Santa Clara, CA, USA) was used as stationary phase with the guard column Zorbax SB-C18 (4.6 × $12.5 \mathrm{~mm}$, $5 \mu \mathrm{m}$ particle size, Agilent, Santa Clara, CA, USA). At these conditions, cholesterol was eluted in $2.2 \mathrm{~min}$. Data were recorded and treated using the OpenLab CDS software, ChemStation Edition for LC, and LC/MS systems (product version A.01.08.108).

\section{Preparation of crosslinked $\beta C D c T A$}

$\beta$ CDcTA was prepared according to Han et al. (2005) as follows: $10 \mathrm{~g}$ of $\beta-\mathrm{CD}$ were mixed with $8 \mathrm{~mL}$ of distilled water and the suspension was magnetically stirred at room temperature for $2 \mathrm{hrs}$. Then, $0.2 \mathrm{~g}$ of tartaric acid was added, $\mathrm{pH}$ was adjusted to $\mathrm{pH}=10$ with $1 \mathrm{~mol} / \mathrm{L} \mathrm{NaOH}$ and the 
reaction mixture was stirred for $1.5 \mathrm{hrs}$; the product was then readjusted to $\mathrm{pH}=5$ with acetic acid. Finally, $\beta$ CDcTA was recovered by filtering through Whatman paper No. 2, washed three times with $15 \mathrm{~mL}$ of distilled water, dried at $60{ }^{\circ} \mathrm{C}$ for $20 \mathrm{hrs}$ and passed through a 100 mesh sieve.

\section{Cholesterol removal}

Each sample of $10 \mathrm{~g}$ of milk was placed in a beaker and different amounts of BCDcTA (1.0, 2.0 or $5.0 \%)$ were added. The mixtures were stirred at $150 \mathrm{rpm}$ using a magnetic blender (MM1, Laboratorní přistroje Praha, Czech Republic) for $15 \mathrm{~min}$ at $23^{\circ} \mathrm{C}$ and centrifuged at $166 \mathrm{~g}$ (5430 R Eppendorf, Hamburg, Germany) for $10 \mathrm{~min}$. After centrifugation, the milk supernatant was analysed for cholesterol content. All procedures were duplicated.

\section{Acquisition of statistical data}

Statistical data on annual food consumption in the Slovak Republic were obtained from the latest annual report - Food Consumption in the Slovak Republic in 2018 (Sitárová, 2019).

\section{Results and Discussion}

\section{Determination of cholesterol content}

For the determination of cholesterol content in milk, an in-house validated HPLG method was applied (Kolarič and Šimko, 2020b). At the given conditions, chromatographic separation of cholesterol was sufficient which was confirmed by UV spectra of the cholesterol standard and cholesterol in milk. As follows from Figure 1, the spectra are practically identical with the peak ratio parameter approaching 1 .

For illustration, chromatographic record of cholesterol standard analysis and milk analysis are shown in Figures 2 and 3.

\section{Cholesterol removal degree}

Efficiency of cholesterol removal in dependence on $\beta C D c$ TA addition is shown in Table 1.

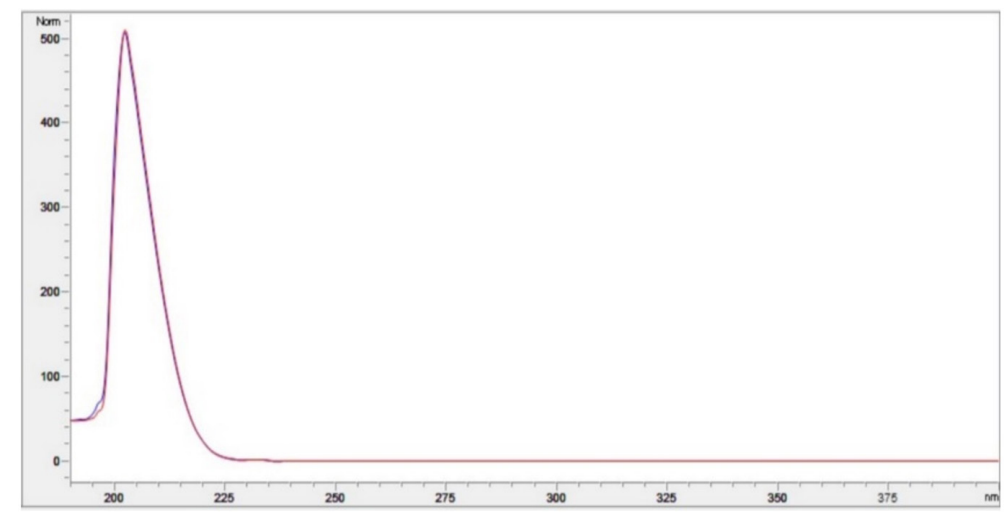

Fig. 1. Comparison of UV spectra of cholesterol standard (red line) and cholesterol in milk (blue line).

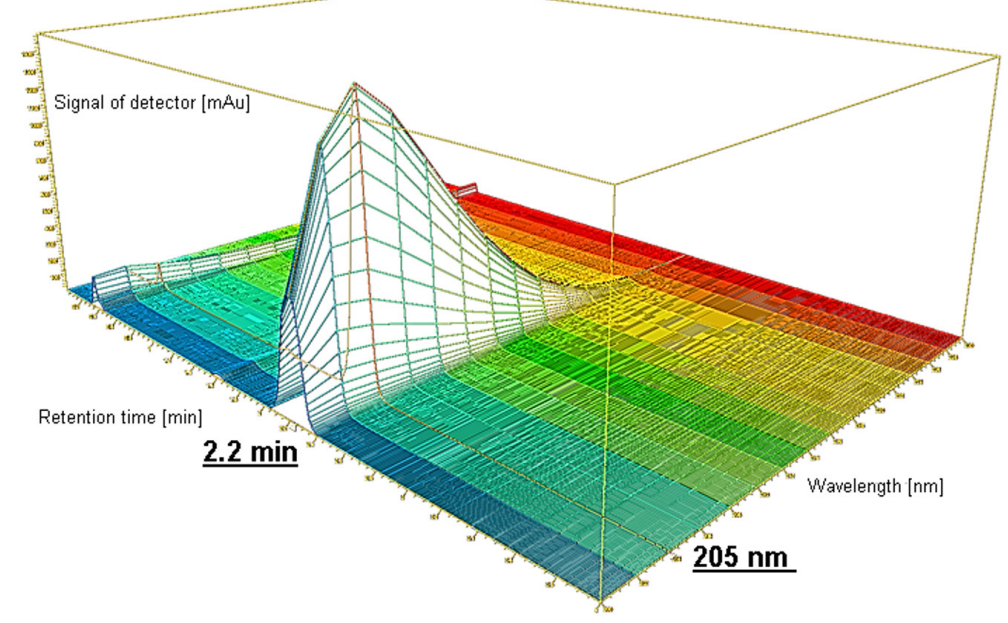

Fig. 2. 3D HPLC record of cholesterol standard analysis. 


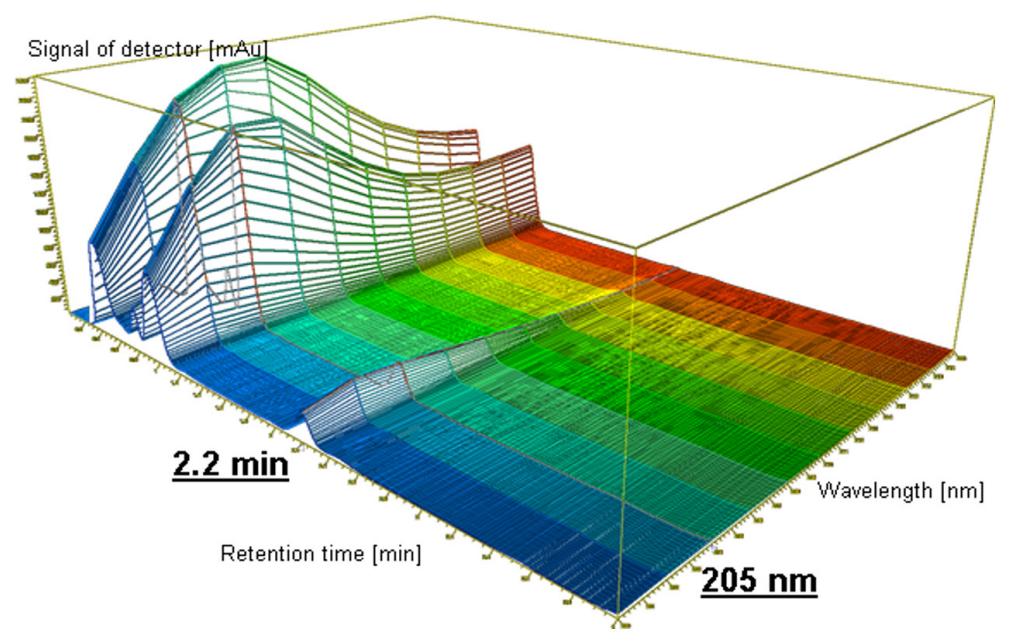

Fig. 3. 3D HPLC record of cholesterol in milk analysis.

Tab. 1. Removal of cholesterol from milk by $\beta$ CDcTA addition.

\begin{tabular}{|c|c|c|c|c|}
\hline $\begin{array}{c}\beta \mathrm{CDcTA} \text { addition } \\
{[\%]}\end{array}$ & Signal [mAU.s $]$ & $\begin{array}{c}\text { Cholesterol content } \\
{[\mathrm{mg} / \mathrm{kg}]}\end{array}$ & $\operatorname{RSD}[\%]$ & $\begin{array}{c}\text { Cholesterol } \\
\text { removal degree } \\
{[\%]}\end{array}$ \\
\hline 0 & $660.02 \pm 59.60$ & $92.78 \pm 9.57$ & 10.3 & - \\
\hline 1 & $405.53 \pm 64.86$ & $31.23 \pm 4.92$ & 15.8 & 66.3 \\
\hline 2 & $209.63 \pm 18.89$ & $15.58 \pm 1.39$ & 8.9 & 83.2 \\
\hline 5 & $175.90 \pm 20.50$ & $13.57 \pm 1.57$ & 11.6 & 85.4 \\
\hline
\end{tabular}

Tab. 2. Per capita food consumption in the Slovak Republic in 2018, consumption by commodity and calculated original and reduced cholesterol content.

\begin{tabular}{|c|c|c|c|c|c|c|}
\hline A & B & C & $\mathrm{D}$ & $\mathrm{E}$ & $\mathrm{F}$ & G \\
\hline Commodity & $\begin{array}{c}\text { Consumption } \\
\text { per capita* } \\
{[\mathrm{kg}]}\end{array}$ & $\begin{array}{c}\text { Cholesterol } \\
\text { content** } \\
{[\mathrm{mg} / \mathrm{kg}]}\end{array}$ & $\begin{array}{c}\text { Cholesterol } \\
\text { daily intake } \\
\text { by commodity } \\
\text { [mg] }\end{array}$ & $\begin{array}{c}\text { Cholesterol } \\
\text { daily intake by } \\
\text { commodity } \\
{[\%]}\end{array}$ & $\begin{array}{c}\text { Reduced } \\
\text { cholesterol } \\
\text { daily intake } \\
\text { [mg] }\end{array}$ & $\begin{array}{c}\text { Reduced } \\
\text { cholesterol daily } \\
\text { intake by commodity } \\
{[\%]}\end{array}$ \\
\hline $\begin{array}{l}\text { Milk (including } \\
\text { dairy products } \\
\text { without butter) }\end{array}$ & 171.1 & 130.0 & 60.9 & 16.5 & 8.9 & 3 \\
\hline Butter & 3.4 & 2690.0 & 25.1 & 6.8 & 3.7 & 1.2 \\
\hline Lard & 3.3 & 950.0 & 8.6 & 2.3 & 8.6 & 2.9 \\
\hline Pork meat & 35.4 & 690.0 & 66.9 & 18.1 & 66.9 & 22.6 \\
\hline Beef meat & 5.2 & 720.0 & 10.3 & 2.8 & 10.3 & 3.5 \\
\hline Poultry meat & 22.2 & 730.0 & 44.4 & 12.0 & 44.4 & 15.0 \\
\hline Fish & 5.5 & 630.0 & 9.5 & 2.6 & 9.5 & 3.2 \\
\hline Eggs & 13.7 & 3840.0 & 144.1 & 39.0 & 144.1 & 48.6 \\
\hline Sum & & & 369.8 & 100.0 & 296.3 & 100.0 \\
\hline
\end{tabular}

*data taken from Sitárová, 2019.

**data taken from Frida, 2020.

As it follows from the measured data, intensity of cholesterol removal depends on the amount of $\beta C D c T A$ added to treated milk. Thus, while at the $1 \%$ addition of $\beta$ CDcTA, the cholesterol content decreased by $66.3 \%$, at the $5 \%$ addition, it decreased by $85.4 \%$. These results are a little worse in comparison with data published by Han et al. (2005) who were able to decrease cholesterol con- 
tent in the range of 92.1 to $93.1 \%$. On the other hand, cholesterol decrease achieved by Kim et al. (2004) was in the range of 79.4 to $83.3 \%$ when applying $\beta$-CD crosslinked with epichlorohydrin.

\section{Evaluation of statistical data}

Primary data on to average food consumption in 2018 were obtained from Sitárová (2019). As follows from Table 2 column A, these statistical data show per capita consumption of milk (as milk itself and dairy products) and butter, what is critical for the evaluation of "milky" cholesterol data. However, also other food commodities participate on total cholesterol intake. To estimate the total per capita daily cholesterol intake in Slovak population, data on cholesterol content in individual food commodities were taken from the Danish food database Frida (2020). Cholesterol content in individual commodities is shown in column $\mathrm{C}$ while daily per capita cholesterol intake in $\mathrm{mg}$ and \% are displayed in columns D and E. As it can be seen from these data, per capita daily cholesterol intake in 2018 reached the value of $369.8 \mathrm{mg}$, which is really high as this includes total Slovak population including suckling infants, vegetarians or even vegans. Therefore, it is reasonable to assume that daily cholesterol intake in some social groups exceeds the recommended value of $300 \mathrm{mg}$ by twice, which is seriously threating health, or even life considering long duration of this situation. Hence, decreasing cholesterol content in milk and its products by $85.4 \%$, enables decreasing the per capita daily cholesterol intake from $369.8 \mathrm{mg}$ to $296.3 \mathrm{mg}$ (column F), which is below the recommended value and the portion of cholesterol intake from milk and dairy products would decrease from $23.3 \%$ to $4.2 \%$ (column $\mathrm{G}$ ) in total cholesterol balance. For comparison, mean cholesterol intake of the overall US population had been relatively constant at $\sim 290 \mathrm{mg} /$ day in 2001-2014 (Xu et al. 2018). So, by removal of cholesterol from milk and dairy products, health effects of dairy products can be considerably strengthened while the consumption of full-fat dairy products contributes to higher intakes of significant nutrients such as calcium, vitamins $\mathrm{D}$ and $\mathrm{K}$ and other bioactive compounds (Loran et al., 2018).

\section{Conclusion}

Summarising the results, information, data, and findings obtained in this study, the following conclusions can be postulated:

a) Cholesterol content in milk (and dairy products produced from milk) can be effectively decreased by $\beta$ CDcTA addition b) The addition of $5 \%$ of $\beta$ CDcTA results in cholesterol content decrease by $85.4 \%$ in treated milk

c) Application of such treated milk in food production can decrease the total cholesterol average daily intake per capita in Slovak population from the current value of $369.8 \mathrm{mg}$ to $296.3 \mathrm{mg}$, weakening health problems associated with long duration of high intake of cholesterol contained in foods of animal origin.

\section{Conflict of interest}

Authors declare no conflict of interest. The funders had no role in the design of the study, collection and interpretation of data, writing of the manuscript, or in the decision to publish the results.

\section{Acknowledgements}

This publication was supported by the Operational Program Integrated Infrastructure within the project: Demand-driven research for the sustainable and innovative food, Drive 4SIFood 313011V336, co-financed by the European Regional Development Fund, and co-funded by project "ACCORD" (ITMS project code: 313021X329) supported by the Operational Programme Research and Development funded by the European Regional Development Fund and the grant APVV-061-2018.

\section{References}

Albuquerque TG, Oliveira MBPP, Sanches-Silva A, Costa HS (2016) Food Chemistry 193: 18-25.

Alonso L, Cuesta P, Fontecha J, Juarez M, Gilliland SE (2009) Journal of Dairy Science 92: 863-869.

Appel LJ, Moore TJ, Obarzanek E, Vollmer WM, Svetkey LP, Sacks FM, Bray GA, Vogt TM, Cutler JA, Windhauser MM et al. (1997) New England Journal of Medicine 336: 1117-1124.

Bauer LC, Santana DA, Macedo MS, Torres AG, de Souza NE, Simionato JI (2014) Journal of the Brazilian Chemical Society 25: 161-168.

Carson JAS, Lichtenstein AH, Anderson CA, Appel LJ, Kris-Etherton PM, Meyer KA, Polonsky T, Van Horn L (2020) Circulation 141: 39-53.

Danish food database Frida (2020) Available online: https://frida.fooddata.dk/ (accessed on 3. October 2020).

Dinh TTN, Thompson LD, Galyean ML, Brooks JC, Patterson KY, Boylan LM (2011) Comprehensive Reviews in Food Science and Food Safety 10: 269-289.

Ference BA, Ginsberg HN, Graham I, Ray KK, Packard CJ et al. (2017) European Heart Journal 38: 2459-2472.

Fung TT, McCullough ML, Newby PK, Manson JE, Meigs JB, Rifai N, Willett WC, Hu FB (2005) American Journal of Clinical Nutrition 82:163-173.

Han EM, Kim SH, Ahn J, Kwak HS (2005) AsianAustralasian Journal of Animal Sciences 18: 1794-1799.

Kim SH, Ahn J, Kwak HS (2004) Archives of Pharmacal Research 27: 1183-1187.

Kolarič L, Šimko P (2020a) Potravinárstvo Slovak Journal of Food Sciences 14: 118-124. 
Kolarič L, Šimko P (2020b) Foods 9: 1378.

Larsson SC, Virtamo J, Wolk A (2012) Atherosclerosis 221: 282-286.

Lordan R, Tsoupras A, Mitra B, Zabetakis I (2018) Foods, 7, 29-34.

Li LH, Dutkiewicz EP, Huang YC, Zhou HB, Hsu CC (2019) Journal of Food and Drug Analysis 27: 375-386.

Official Report of Ministry of Health of Slovak Republic (2015) 63: 22-27. Available online: https://www.uvzsr. sk/docs/info/hv/Recommended_Nutrition_Doses_ for_Population_of_the_Slovak_Republic.pdf; https:// www.uvzsr.sk/index.php?option $=$ com_content\&vi ew $=$ article\&id=1014: od poruane-vyivove-davky-preobyvatestvo-vnslovenskej-republike\&catid=66: vyiva-abezpenos-potravin\&Itemid $=72$

(accessed on 30. September 2020).
Mach F, Baigent C, Catapano AL, Koskinas KC, Casula M, Badimon L et al. (2020) European Heart Journal 41: 111-188.

Parish EJ, Boos TL, Shengrong L (2002) The chemistry of waxes and sterols. In: Akoh CG, Min DB (Eds) Food Lipids, pp. 103-131. Marcel Dekker, New York.

Sitárová T (2019) Food Consumption in the SR in 2018, pp. 10-17. Statistical Office of the Slovak Republic, Bratislava.

Xu Z, McClure ST, Appel LJ (2018) Nutrients 10: E771. 